\title{
Budi Daya Lisianthus (Eustoma grandiflorum (Raf.) Shinn.) di Mayungan, Bali
}

\author{
Cultivation of Lisianthus (Eustoma grandiflorum (Raf.) Shinn.) at Mayungan, Bali
}

\author{
Antony Demas, Dewi Sukma dan Juang Gema Kartika \\ Departemen Agronomi dan Hortikultura, Fakultas Pertanian, Institut Pertanian Bogor \\ (Bogor Agricultural University), Jl. Meranti, Kampus IPB Darmaga, Bogor 16680, Indonesia \\ Telp.\& Faks.62-251-8629353 e-mail agronipb@indo.net.id \\ *Penulis untuk korespondensi: dsukma70@yahoo.com
}

Disetujui 14 November 2016 / Published online 8 Desember 2016

\begin{abstract}
Objectives of this research were to increase basic knowledge and skills related to practical field work experiences on lisianthus (Eustoma grandiflorum (Raf.) Shinn.) cultivation.The apprenticeship was held at Mayungan, Bali from February umtil June 2009. During the time, the occupation as a laborer, supervisor assistant, and manager assistant. Several datas were obtained through interviews and discussions with workers and manager, in addition to direct observations on fields. These were including informations in relation to company profile, soil condition, planting construction, and employment matters. Lisianthus cultivation facts, such as plants development in nursery and greenhouse, plant characteristics, irrigation method, fertilizer, productive plants percentage, the spread of harvest, and vase-life had been observed. Lisianthus has unique characteristics as a cut flower crop besides it's varies among it's own varieties. These includes cultivation method not only from maintaining young plants on plug production but also growing lisianthus in greenhouse production, until post harvest handling. Nevertheless, there is a lack in plants productivity that seems very low. Exclusively on production and marketing systems in order to compete against other experienced and well-maintained cutflower growers.
\end{abstract}

Keywords : cultivation, Eustoma grandiflorum, Lisianthus

\begin{abstract}
ABSTRAK
Tujuan dari penelitian ini adalah untuk meningkatkan pengetahuan dan keterampilan dasar yang berkaitan dengan pengalaman praktik kerja lapangan pada budi daya lisianthus (Eustoma grandiflorum (Raf) Shinn.). Penelitian dilaksanakan di Mayungan, Bali dari Februari - Juni 2009. Selama penelitian berlangsung, pekerjaan yang dilakukan sebagai buruh, pengawas asisten, dan asisten manajer. Beberapa data diperoleh melalui wawancara dan diskusi dengan pekerja dan manajer, selain itu juga pengamatan langsung di lapangan. Informasi yang diperoleh berkaitan dengan profil perusahaan, kondisi tanah, konstruksi penanaman, dan kendala pekerjaan. Fakta budi daya lisianthus, seperti pengembangan tanaman di pembibitan dan rumah kaca, karakteristik tanaman, metode irigasi, pupuk, persentase tanaman produktif, sebaran panen, dan vase life telah diamati. Lisianthus memiliki karakteristik yang unik sebagai tanaman bunga potong, selain itu bervariasi antar varietasnya. Metode budidayanya tidak hanya merawat tanaman muda pada plug produksi tetapi juga menumbuhkan lisianthus dalam rumah kaca produksi, hingga penanganan pascapanen. Terdapat kekurangan dalam produktivitas tanaman yang terlihat sangat rendah. Secara khusus pada produksi dan sistem pemasaran dalam rangka untuk bersaing dengan petani bunga potong berpengalaman dan terlatih.
\end{abstract}

Kata kunci: budi daya, Eustoma grandiflorum, Lisianthus 


\section{PENDAHULUAN}

Bisnis bunga dan tanaman hias di Indonesia semakin berkembang pesat (Sari, 2008). Laws (2007) mengemukakan bahwa saat ini Indonesia mengekspor bunga potong senilai kurang dari \$5 juta per tahun. Hal ini menjadikan Indonesia Negara ke- 33 terbesar dalam ekspor bunga potong, dengan pangsa pasar dunia sebesar $0.07 \%$.

Lisianthus memiliki sejumlah kualitas dari kriteria sebuah "bunga potong yang ideal" (Maryland Cooperative Extension, 2000). Pada tahun 1995, lisianthus ditempatkan pada peringkat ke-11 dalam pasar bunga potong Belanda (Ledger et al., 1997). Sejak itu, kepopuleran lisianthus terus menanjak dari tahun ke tahun. Berdasarkan Harbaugh (2007), lisianthus menjadi bunga potong nomor satu dengan penjualan mencapai lebih dari 129 juta tangkai pada tahun 2001 di Jepang, dan termasuk ke dalam daftar 10 bunga potong urutan teratas di Eropa dengan tingkat penjualan sedikitnya 122 juta tangkai pada tahun 2001.

Bunga Lisianthus masih belum banyak dibudidayakan di kalangan petani Indonesia, teknologi yang diterapkan masih relatif sedikit (Hedy, 2008). Lisianthus sudah sepatutnya untuk terus dikembangkan dalam upaya peningkatan popularitasnya di masa mendatang. Oleh karena itu, perlu diamati teknik budidaya yang baik untuk mencapai produksi lisianthus yang optimum dengan kualitas yang baik. Tujuan dari kegiatan penelitian ini adalah mempelajari teknik budidaya tanaman lisianthus, meningkatkan pengetahuan dan keterampilan mahasiswa dalam kegiatan budi daya serta manajemen kebun yang dikembangkan di Mayungan, Bali.

\section{BAHAN DAN METODE}

Penelitian dilaksanakan di di Banjar Mayungan, Desa Antapan, Kecamatan Baturiti, Tabanan, Bali yang dimulai Februari - Juni 2009.

Metode yang dilaksanakan pada kegiatan penelitian adalah praktik kerja langsung di perusahaan. Data primer diperoleh dengan hasil kegiatan wawancara dan diskusi dengan manajer dan karyawan, serta hasil pengamatan langsung di lapang, sedangkan data sekunder didapat dari arsip dan studi literatur berupa kondisi perusahaan, tanah, bangunan tanam, dan tenaga kerja. Pengamatan yang dilakukan terdiri dari perkembangan lisianthus di pembibitan, penyiraman, perkembangan bunga, vase life, karakteristik tanaman lapang, persentase tanaman produktif.

\section{HASIL DAN PEMBAHASAN}

\section{Keadaan Umum}

Keadaan tanah lahan produksi cukup subur dengan $\mathrm{pH}$ tanah 5.5-7 dan jenis tanah latosol. Menurut Kantor Klimatologi Kecamatan Pancasari (2008), tahun 2008 curah hujan mencapai 4200 $\mathrm{mm} /$ tahun dengan jumlah hari hujan 199 hari. Sedangkan suhu berkisar diantara $15-23{ }^{0} \mathrm{C}$ dengan tingkat kelembaban udara $88 \%$. Lahan yang digunakan terbagi menjadi 2, masing-masing disebut kebun I dan kebun II yang memiliki luas produktif $11000 \mathrm{~m}^{2}$ dan $7000 \mathrm{~m}^{2}$.

\section{Karakteristik Lisianthus}

Varietas yang telah dikembangkan sedikitnya 20 varietas tanaman lisianthus dan semuanya merupakan varietas berbunga ganda. Keunikan masing-masing varietas jelas terlihat dari warna bunganya. Warna bunga lisianthus yang diproduksi antara lain putih, hijau, cream, light purple, deep purple, pink, light pink, dan pink rim. Varietas yang memiliki bunga berwarna putih adalah varietas Picorosa Snow, Yuki Temari, dan Xcalibur Pure White. Setti Green berwarna hijau, sedangkan Paleo Champagne berwarna cream. Bunga berwarna deep purple dimiliki Picorosa Blue dan Carmen Violet, sedangkan light purple dimiliki Rosina Lavender. Picorosa memiliki bunga berwarna pink, sedangkan Lination Pink berwarna light pink. Warna pink rim dimiliki varietas Picorosa Pink Picotee.

Tanaman lisianthus memiliki sistem akar serabut yang tersusun dari akar-akar serabut kecil yang berbentuk benang. Akarnya mampu menembus tanah hingga kedalaman $10-15 \mathrm{~cm}$, yang merupakan panjang akar dari leher batang hingga ke ujungnya. Tanaman lisianthus memiliki batang yang setengah berkayu. Batang tanaman berbentuk bulat yang ukurannya dari pangkal sampai ke ujung tidak besar bedanya. Permukaan batang licin berwarna hijau. Arah tumbuh batang tanaman lisianthus adalah tegak lurus ke atas (erectus). Percabangan lisianthus menggarpu atau dikotom, batang utama tanaman tumbuh kemudian menjadi dua atau tiga cabang yang sama besarnya. Arah pertumbuhan cabang adalah tegak (fascigiatus), sama seperti batang utama sebelum menggarpu.

Kelengkapan daun lisianthus hanya terdiri dari helaian saja tanpa upih ataupun tangkai, sehingga helaian langsung melekat atau duduk pada batang. Daun yang demikian disebut juga sebagai daun duduk (sessilis). Tampak segi bangun atau bentuk (circumscriptio), bagian 
terlebar helaian daun (lamina) lisianthus berada di tengah-tengah helaian daun dengan bentuk bangun jorong (ovalis atau ellipticus), yaitu dengan perbandingan panjang dan lebar daun berkisar antara $1 \frac{1}{2}-2: 1$.

Bunga lisianthus seperti terlihat pada Gambar 1 merupakan bunga lengkap dan sempurna yang terdiri dari bagian-bagian bunga seperti tangkai bunga (pedicellus), dasar bunga (receptaculum), hiasan bunga (perianthium) yang terdiri dari kelopak (kalyx) dan mahkota (corolla), alat kelamin jantan (androecium) dan alat kelamin betina (gynaecium). Tangkai bunga memiliki penampang bulat dan berwarna hijau seperti batang utama. Dasar bunga lisianthus berbentuk rata, yaitu semua bagian bunga duduk sama tinggi di atas dasar bunga. Kedudukan perhiasan bunga lisianthus sama atau sedikit lebih tinggi daripada duduknya putik, sehingga disebut perigin. Daun kelopak (sepala) berwarna hijau, tidak berlekatan satu sama lain atau bebas, dan simetris beraturan berbentuk bintang. Mahkota bunga memiliki sifat simetris beraturan dengan susunan daun-daun mahkota (petala) yang membentuk mangkuk.

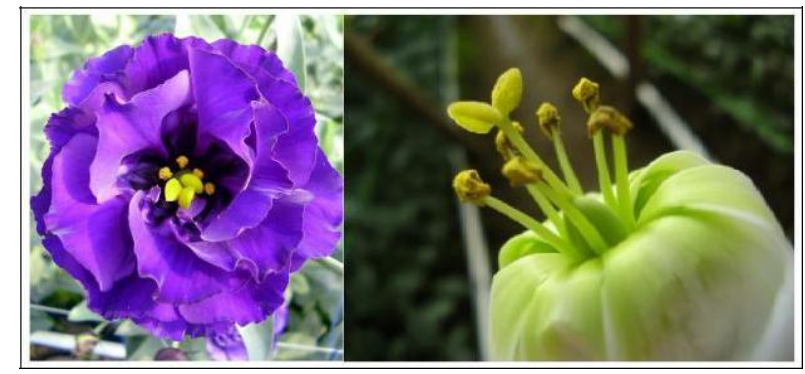

Gambar 1. Bunga Lisianthus

Pengamatan karakteristik lisianthus dilakukan pada 12 varietas, yaitu Yuki Temari, Setti Green, Paleo Champagne, Picorosa Blue, Rosina Lavender, Carmen Violet, Picorosa Rose
Pink, Picorosa Snow, Haru Urara, Lination Pink, Xcalibur Pure White, dan Picorosa Pink Picotee (Lampiran 1).

\section{Pembibitan}

Benih tanaman lisianthus yang digunakan berasal dari Takii Seed dan Sakata Seed, keduanya perusahaan Jepang. Lisianthus yang dibudidayakan merupakan varietas berbunga ganda. Yuki Temari, Setti Green, dan Paleo Champagne merupakan varietas produksi Takii Seed. Varietas produksi Sakata Seed, antara lain Aguropis White, Bridal Snow, Carmen Violet, Exrosa Blue, Picorosa Blue, Rosina Lavender, Rosina Yellow, Rosina Lime, Rosina Green, Rosina Rose Pink, Rosina Pink, Exrosa Lila, Picorosa Rose Pink, Picorosa Snow, Picorosa Pink Picotee, Haru Urara, dan Lination Pink.

Kegiatan di pembibitan lisianthus meliputi sterilisasi tray, persiapan media, penyemaian, dan pemeliharaan. Sterilisasi tray dilakukan dengan cara direndam dalam larutan desinfektan selama kurang lebih 1 menit. Larutan desinfektan yang dipakai adalah $\mathrm{NaClO} \mathrm{5,25 \%} \mathrm{dengan} \mathrm{konsentrasi}$ $3 \mathrm{cc} / \mathrm{L}$.

Media yang digunakan untuk penyemaian adalah campuran cocopeat dengan media campuran dengan nama produk Klassman, produk perusahaan Jerman yang sebagian besar terdiri dari white spahgnum peat. Media Klassman dan cocopeat yang sudah diayak dimasukkan dalam tray berukuran 200 (ukuran $2 \mathrm{~cm} \mathrm{x} 2 \mathrm{~cm}$ per plug) dengan perbandingan 3:2. Sesaat sebelum penanaman, media disiram oleh larutan fungisida sistemik yang mengandung bahan aktif mankozeb $80 \%$ dengan konsentrasi $0.5 \mathrm{~g} / \mathrm{L}$ hingga media basah untuk mengurangi risiko pertumbuhan cendawan. Perkembangan lisianthus selama 10 minggu seperti pada Gambar 2.

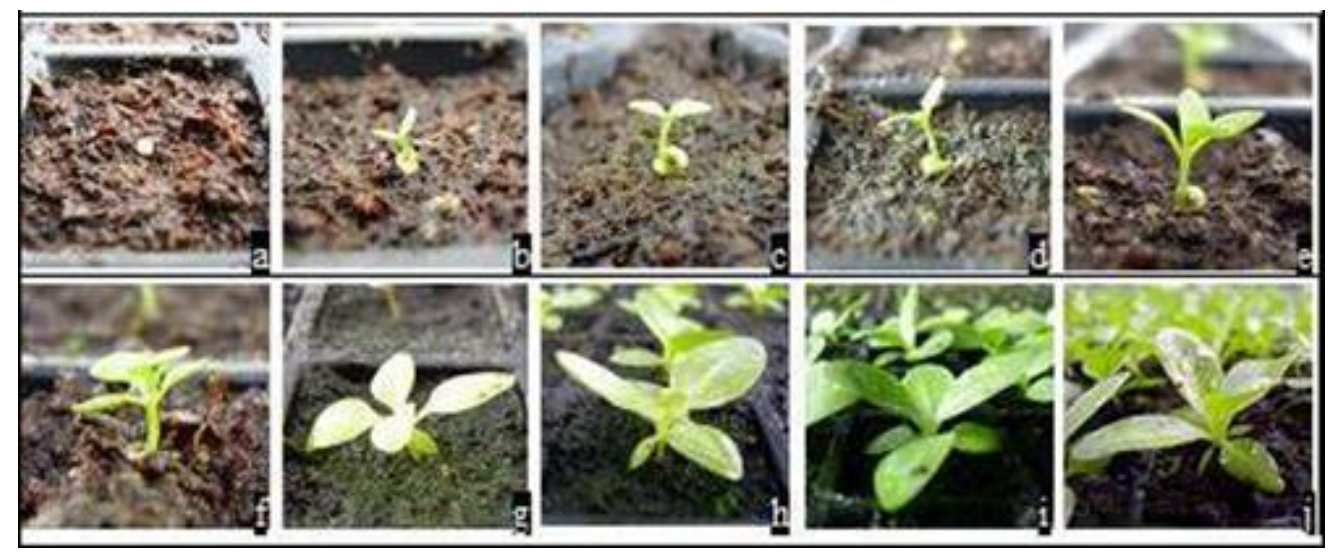

Gambar 2. Perkembangan lisianthus di persemaian (a-j menunjukkan urutan bibit berumur 1-10 minggu) 
Pemeliharaan meliputi penaungan, pengkabutan, pemupukan, transplanting, dan pengendalian hama dan penyakit. Lokasi persemaian lisianthus diberi naungan paranet $70 \%$ lapis ganda dan pada dinding-dindingnya juga dipasang paranet $70 \%$. Paranet atap atau paranet $70 \%$ lapis ganda dibuka dan tutup secara manual untuk mengendalikan suhu. Berdasarkan pengamatan, suhu pembibitan berkisar $16-30{ }^{\circ} \mathrm{C}$.

Tabel 1 menunjukkan lisianthus menunjukkan ketidakserempakan tumbuh selama masa pertumbuhan di pembibitan. Terdapat 7 varietas dari total 14 varietas yang diamati menunjukkan ketidakserempakan tumbuh. Lisianthus dibudidayakan menggunakan benih komersial, yang diproduksi secara masal sebagai lot benih. Menurut Sadjad et al. (1999), daya berkecambah merupakan tolok ukur viabilitas potensial yang menunjukkan kemampuan benih tumbuh pada kondisi optimum, dan menumbuhkan tanaman normal yang berproduksi normal. Persentase daya berkecambah yang tertera pada kemasan yang berasal dari produsen benih baik Takii Seed maupun Sakata Seed adalah $85 \%$. Sementara itu dalam pembibitan yang dilakukan (Tabel 2), berarti hanya terdapat 4 dari 14 varietas yang memiliki persentase daya berkecambah di atas 85\%, yakni Marsmellow White, Xcalibur Pure White, Carmen Violet, dan Lination Pink, dan keempatnya berasal dari Sakata Seed. Tjitrosoepomo (2007) menyatakan bahwa biji hanya akan berkecambah jika mendapat syaratsyarat yang diperlukan, yaitu air, udara, cahaya, dan panas. Sakata Seed America (2007) menyatakan bahwa suhu optimum untuk germinasi lisianthus adalah $21^{\circ} \mathrm{C}$. Takii (2006) menyatakan suhu germinasi sebaiknya berkisar $20-24^{\circ} \mathrm{C}$, sementara suhu ruang pembibitan berkisar pada $16^{\circ} \mathrm{C}$ pada malam hari dan $30^{\circ} \mathrm{C}$ pada siang hari. Tindakan pengkabutan, pembukaan dan penutupan paranet atap masih kurang tepat karena tidak mampu menciptakan temperatur yang optimum serta fluktuasi suhu harian masih sangat besar yaitu mencapai $14{ }^{\circ} \mathrm{C}$.

Tabel 1. Pertumbuhan benih lisianthus pada berbagai varietas

\begin{tabular}{lccc}
\hline \multicolumn{1}{c}{ Varietas } & Jumlah Ulangan & Daya Berkecambah (\%) & Keserempakan Tumbuh \\
\hline Takii Seed : & 3 & $64,09 \pm 18,81$ & Ya \\
$\quad$ Paleo Champagne & 4 & $60,68 \pm 33,46$ & Ya \\
$\quad$ Setti Green & 4 & $52,50 \pm 31,62$ & Tidak \\
$\quad$ Yuki Temari & & & Ya \\
Sakata Seed : & 1 & $96,00 \pm 0,00$ & Tidak \\
$\quad$ Marsmellow White & 6 & $93,33 \pm 3,04$ & Tidak \\
Xcalibur Pure White & 3 & $89,00 \pm 3,61$ & Ya \\
Carmen Violet & 5 & $88,00 \pm 3,86$ & Ya \\
Lination Pink & 1 & $83,21 \pm 1,11$ & Tidak \\
Rosina Yellow & 6 & $81,31 \pm 15,30$ & Tidak \\
Picorosa Pink Picotee & 5 & $76,50 \pm 6,25$ & Tidak \\
Picorosa Snow & 3 & $73,83 \pm 5,06$ & Tidak \\
Picorosa Blue & 5 & $72,65 \pm 5,88$ & Ya \\
Haru Urara & 6 & $63,92 \pm 3,98$ & Ya \\
Picorosa Rose Pink & 4 & $58,75 \pm 18,57$ & \\
$\quad$ Rosina Lavender & & & \\
\end{tabular}

\section{Persiapan Lahan}

Persiapan lahan merupakan kegiatan yang dilakukan sebelum penanaman bibit. Kegiatannya pertama-tama adalah pencabutan tiang-tiang bambu penyangga support net, penggulungan support net, dan pelepasan unit-unit pipa irigasi yang kemudian diletakkan di tepi-tepi green house agar tidak menghalangi kinerja traktor.

Sisa-sisa tanaman dibersihkan dan dibuang ke tempat pembuangan sampah, setelah itu disebarkan media yang terdiri atas campuran cocopeat, kompos daun, pupuk kandang, dan sekam. Media juga dicampurkan dengan bakteri dekomposer yang berasal dari Jepang (Chikara bactery). Jumlah media campuran ditambahkan sesuai kondisi kesuburan tanah, apabila dilakukan penambahan maka media campuran disebar sebanyak 3-3.5 kg/m². Perataan media agar mencapai kedalaman $30 \mathrm{~cm}$ dilakukan dengan pembajakan menggunakan traktor.

Sterilisasi lahan dilakukan saat persiapan lahan menggunakan dazomet $98 \%$ pada saat tingkat serangan nematoda yang tinggi. Lahan yang telah ditaburi dazomet diolah menggunakan traktor, setelah tercampur rata maka tanah ditutup menggunakan plastik (UV) dalam keadaan rapat dengan cara membenamkan ujung-ujung plastik ke dalam tanah. Jangka waktu minimal yang dibutuhkan untuk sterilisasi ini adalah 2 minggu. 


\section{Persiapan Tanam}

Pembuatan bedengan dengan ukuran lebar $1.2 \mathrm{~m}$ dan panjang sesuai panjang greenhouse dilakukan sebelum penanaman. Jarak antar bedeng sepanjang $40 \mathrm{~cm}$ rata dengan bedeng. Kegiatan selanjutnya adalah pemasangan unit-unit pipa irigasi, tiang-tiang bambu penyangga support net (end support) dan support net. Instalasi irigasi menggunakan pipa $1 / 2$ inch bernozzle dengan jarak $0.5 \mathrm{~m}$ dan ditempatkan dikedua tepi bedeng di atas permukaan bidang tanam. End support berupa tiang dari bambu yang ditempatkan diujung dan disamping kiri-kanan bedeng dan diantaranya membentang sebilah bambu yang dapat dimobilisasi sebagai penyangga support net. Penyangga tajuk tanaman agar tidak rebah dan acuan jarak tanam digunakan support net berupa jaring dari tali tambang plastik. Support net dibuat dengan lebar $\pm 1.2 \mathrm{~m}$ yang terdiri dari 9 kotak masing-masing berjarak $12.5 \mathrm{~cm}$, sedangkan panjangnya disesuaikan dengan panjang bedeng.

Penyiraman dilakukan hingga kondisi tanah basah dan tidak berdebu. Penyiraman harus dilakukan dengan homogen karena tahap awal pertumbuhan bibit dapat mempengaruhi keserempakan pertumbuhan tanaman lisianthus. Tanah yang kering akan menyebabkan tanaman layu dan terhambat pertumbuhannya, sehingga penanaman sering terlihat kurang merata. Lahan diberi herbisida pra tumbuh oksifluorfen $240 \mathrm{~g} / \mathrm{L}$ dengan konsentrasi $1 \mathrm{cc} / \mathrm{L}$ pada waktu seminggu sebelum tanam. Herbisida membentuk lapisan transparan di atas permukaan tanah yang diharapkan mampu menekan laju pertumbuhan gulma. Pupuk dasar yang diberikan tiga hari sebelum tanam berupa NPK 16-16-16 dengan dosis $40 \mathrm{~g} \mathrm{~m}^{-2}$ dan SP-36 dengan dosis $40 \mathrm{~g} \mathrm{~m}^{-2}$ dengan cara ditabur.

\section{Penanaman}

Lisianthus yang siap ditanam merupakan tanaman yang berumur minimal 10 minggu yang telah memiliki minimal 6 helai daun. Hal ini sesuai menurut pendapat Highsun Express (2008) bahwa penanaman bibit lisianthus dilakukan saat tanaman muda dan tumbuh aktif, yang memiliki 4-6 helai daun. Menurut Maryland Cooperative Extension (2000), bibit lisianthus siap tanam merupakan bibit yang berumur 10 minggu.

Penanaman baik dilakukan pada saat cahaya matahari tidak terlalu terik, yaitu pagi ataupun sore hari, agar tanaman tidak mudah layu. Jarak tanam lisianthus adalah $12.5 \mathrm{~cm} \mathrm{x} 12.5 \mathrm{~cm}$. Penanaman dilakukan dengan cara membenamkan bibit ke dalam lubang tanam sedemikian rupa, sehingga seluruh akar dan leher akar (pangkal batang) tertimbun tanah.

\section{Pemeliharaan}

Pemeliharaan tanaman meliputi penyiraman, pemupukan, pembersihan gulma, disbudding, perompesan, menaikkan support net dan pengendalian hama dan penyakit. Sistem irigasi lisianthus menggunakan Gates peripheral irrigation system. Sistem irigasi Gates terdiri dari pipa plastik yang mengelilingi bedeng dari samping kiri-kanan dan kedua ujungnya dengan nozzle plastik dipasang pada tiap jarak tertentu (Mastalerz, 1977). Pengamatan volume air yang dikeluarkan 3 nozzle dalam penyiraman selama 3 menit masing-masing $1540 \mathrm{ml}, 1050 \mathrm{ml}$, dan 1 $460 \mathrm{ml}$. Hasil perhitungan menunjukkan volume penyiraman lisianthus berada pada kisaran 3.5-5.8 $\mathrm{L} \mathrm{m}^{-2}$. Volume penyiraman lisianthus ini tidak jauh berbeda dengan kebutuhan air untuk penyiraman rutin chrysanthemum yang biasanya sekitar 3-5 L $\mathrm{m}^{-2}$ (Cahyono, 1999). Tensiometer yang dipasang di tiap bedeng mampu mengukur potensial air dalam tanah, membantu staf untuk menentukan frekuensi dan volume penyiraman sesuai dengan intuisinya sehingga dapat digunakan untuk mencapai kondisi sesuai keinginan terutama yang berhubungan dengan penyiraman.

Pupuk yang digunakan terdiri dari 3 jenis antara lain $\mathrm{CaNO}_{3}$, NPK 18-18-18, dan $\mathrm{KNO}_{3}$. Penentuan jenis, dosis, serta waktu pemupukan lisianthus berdasarkan pengalaman kru manajerial dalam budi daya tanaman lisianthus secara umum. Menurut Maryland Cooperative Extension (2000), pemupukan dapat menggunakan pupuk NPK 15-015. Menurut Highsun Express (2008), alternatif pemupukan dapat menggunakan pupuk slowrelease selama 3 bulan setelah tanam, selain itu pemupukan dengan pupuk yang mengandung komposisi unsur $\mathrm{N}$ dan $\mathrm{K}$ yang sama juga dapat dilakukan disetiap kali pemupukan dengan konsentrasi 200 ppm. Menurut Sakata Seed America (2007) menggunakan pupuk kalsium nitrat untuk meningkatkan kekuatan batang. Penentuan jenis dan dosis pemupukan sebaiknya didasarkan pada hasil analisis tanah, sedangkan waktu pemupukan didasarkan pada hasil pengamatan berkala mengenai kandungan unsur hara dalam tanah.

Hama dan penyakit yang menyerang tanaman lisianthus tidak menentu, sehingga pengendalian yang dilakukan diselaraskan dengan serangan pada saat itu. Terdapat hama dan penyakit yang merugikan tanaman lisianthus yaitu ulat dan penyakit layu fusarium. Hama ulat dapat dikendalikan secara mekanis yaitu dengan 
melapisi seluruh dinding green house dengan menggunakan insect screen dan juga memasang kertas perangkap serangga (yellow trap) dengan bantuan bambu belahan sebagai penyangga dan dipasang pada jarak kurang lebih 5 meter di setiap bed. Pencegahan kimiawi dengan penyemprotan pestisida yang tepat seperti pada Tabel 2 untuk menekan populasi hama dan serangan penyakit.

Penyakit layu yang menyerang tanaman lisianthus diduga merupakan penyakit layu fusarium yang disebabkan oleh fungi Fusarium sp. Menurut Maryland Cooperative Extension (2000), saat fusarium menyerang perakaran, struktur akar mejadi lembut dan berwarna kecoklatan. McGovern et al. (1998) menyatakan bahwa Fusarium sp. pada utamanya menyerang pangkal batang tanaman lisianthus, tetapi juga dapat menyebabkan busuk pada akar. Layu dan busuk pangkal batang hingga berwarna kecoklatan merupakan gejala dari proses infeksi dan tidak lama kemudian tanaman akan mati. Nekrosis juga terjadi pada pembuluh batang tanaman. Fusarium sp. dapat menyebar dari tray ataupun alat pemangkas, seperti gunting untuk pruning.

Tabel 2. Penggunaan pestisida untuk lisianthus

\begin{tabular}{|c|c|c|c|}
\hline Bahan Aktif & Nama Dagang & Pengendalian & Konsentrasi Pemakaian \\
\hline Mankozeb $80 \%$ & $\begin{array}{l}\text { Bazoka } 80 \\
\text { WP }\end{array}$ & Busuk Batang & $0.5 \mathrm{~g} \mathrm{~L}^{-1}$ \\
\hline Propamocarb hidrochloride $722 \mathrm{~g} \mathrm{~L}^{-1}$ & Previcur N & Busuk Batang & $0.3 \mathrm{cc} \mathrm{L}^{-1}$ \\
\hline Metonil $40 \%$ & Lannate $40 \mathrm{SP}$ & Ulat & $0.5 \mathrm{~g} \mathrm{~L}^{-1}$ \\
\hline Spinosad $120 \mathrm{~g} \mathrm{~L}^{-1}$ & Tracer $120 \mathrm{EC}$ & Ulat & $1.0 \mathrm{cc} \mathrm{L}^{-1}$ \\
\hline Emamektin Benzoat 5\% & Proclaim 5 SG & Ulat & $0.1 \mathrm{~g} \mathrm{~L}^{-1}$ \\
\hline Imidacloprit $200 \mathrm{~g} \mathrm{~L}^{-1}$ & BM Imida200 SC & Ulat & $0.25 \mathrm{cc} \mathrm{L}^{-1}$ \\
\hline Benomil $50.4 \%$ & Masalgin $50 \mathrm{WP}$ & Penyakit Layu & $0.5 \mathrm{~g} \mathrm{~L}^{-1}$ \\
\hline
\end{tabular}

Perompesan daun diupayakan sedikit dan tidak lebih dari $25 \%$ dari total jumlah daun pada tanaman. Pertumbuhan jumlah daun lisianthus cukup pesat pada minggu ke-8 dan minggu ke-9 (Gambar 3). Pertambahan jumlah daun paling pesat dimiliki Haru Urara yaitu sebanyak 12.25 helai pada minggu ke-8. Beberapa varietas yang titik puncak pertambahan jumlah daunnya juga berada pada minggu ke-8 antara lain adalah Yuki Temari, Setti Green, dan Xcalibur Pure White.

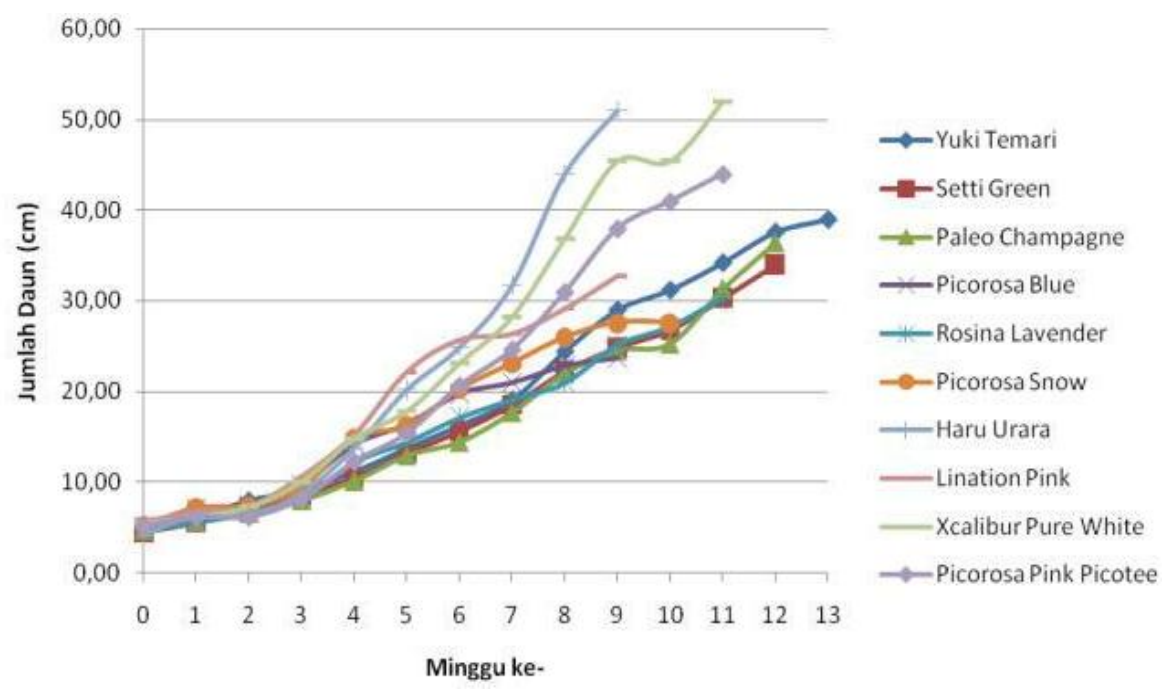

Gambar 3. Grafik pertumbuhan jumlah daun berbagai varietas lisianthus

\section{Panen}

Panen pertama lisianthus untuk tiap varietas berbeda, berkisar dari 11-14 MST. Satu varietas lisianthus dalam satu waktu tanam memiliki periode panen 3 hingga 6 minggu lamanya. Lamanya periode panen ini disebabkan oleh ketidakserempakan waktu pembungaan. Ketidakserempakan waktu pembungaan ini diduga karena kondisi bibit yang bervariasi atau kurang seragam. Gambar 4 menunjukkan hasil pengamatan yang dilakukan terhadap lama perkembangan bunga berukuran satu ruas ibu jari orang dewasa $( \pm 3.5 \mathrm{~cm} \times 2 \mathrm{~cm})$. 

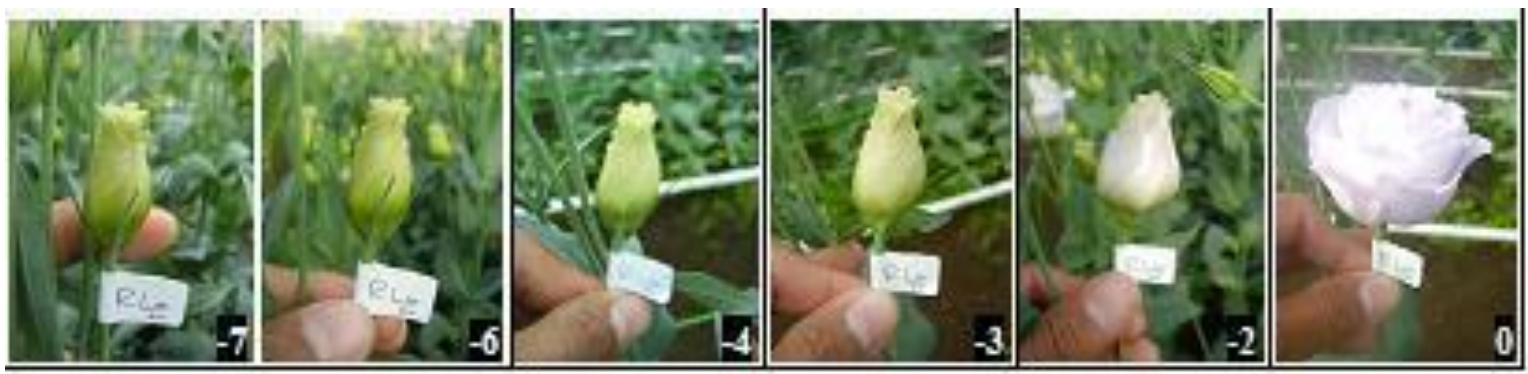

Gambar 4. Perkembangan bunga lisianthus varietas rosina lavender

Pemanenan lisianthus dilakukan dengan syarat terdapat minimal 2 bunga kembar yang mekar dan 2 kuntum bunga yang siap mekar dalam satu tanaman, yaitu bunga kedua dan ketiga. Umumnya pemanenan dilakukan pada saat tanaman berumur 11-14 minggu. Panen dilakukan bertahap sesuai dengan kriteria panen. Lisianthus dipanen selama 3-6 minggu dalam satu kali masa tanam.
Total 12 varietas lisianthus yang diamati pada Tabel 3 hanya terdapat 3 varietas saja yang memiliki persentase tanaman produktif diatas 50 $\%$. Persentase tanaman produktif lisianthus yang begitu rendah disebabkan oleh dua hal, pertama adalah penyakit layu yang menyerang tanaman mulai dari tanaman masih muda hingga layak panen, dan kedua adalah banyaknya tanaman yang mengalami roset.

Tabel 3. Hasil panen berbagai varietas lisianthus

\begin{tabular}{clccc}
\hline Minggu tanam & \multicolumn{1}{c}{ Varietas } & Populasi (tanaman) & Total panen (tanaman) & Tanaman produktif (\%) \\
\hline 9 & Xcalibur Pure White & 756 & 535 & 70,77 \\
9 & Picorosa Pink Picotee & 678 & 470 & 69,32 \\
9 & Rosina Lavender & 228 & 130 & 57,02 \\
9 & Picorosa Blue & 288 & 115 & 39,93 \\
9 & Haru Urara & 528 & 180 & 34,09 \\
7 & Yuki Temari & 1074 & 359 & 33,43 \\
7 & Paleo Champagne & 1158 & 372 & 32,12 \\
7 & Setti Green & 762 & 235 & 30,84 \\
9 & Lination Pink & 672 & 120 & 17,86 \\
9 & Picorosa Snow & 588 & 89 & 15,14 \\
9 & Picorosa Rose Pink & 480 & 37 & 7,71 \\
9 & Carmen Violet & 354 & 25 & 7,06 \\
& Total & 7566 & 2667 & 35,25 \\
\hline
\end{tabular}

\section{Pascapanen}

Pascapanen dilakukan dengan memasukkan bunga ke dalam air yang sudah diberi larutan pengawet (preservatif) setelah dibungkus. Larutan tersebut adalah Chrysal dengan konsentrasi 2cc $\mathrm{L}^{-1}$ selama 3-4 jam. Menurut Boodley (1998), bahan kimia yang efektif sebagai larutan preservatif bunga potong adalah 8hydroxyquinoline sulfate (8-HQS) dan 8hydroxyquinoline citrate (8-HQC). Bahan kimia efektif menurut Nelson (1978), dari larutan preservatif yang sering dipakai, didalamnya terkandung 8-HQC dan sukrosa (gula pasir).

Berdasarkan Tabel 4 perlakuan menggunakan larutan desinfektan, Chrysal, dan gula mampu meningkatkan umur vase life lisianthus, namun larutan campuran gula dan desinfektan menurunkan vase life lisianthus.
Tabel 4. Hasil uji vase life beberapa varietas lisianthus

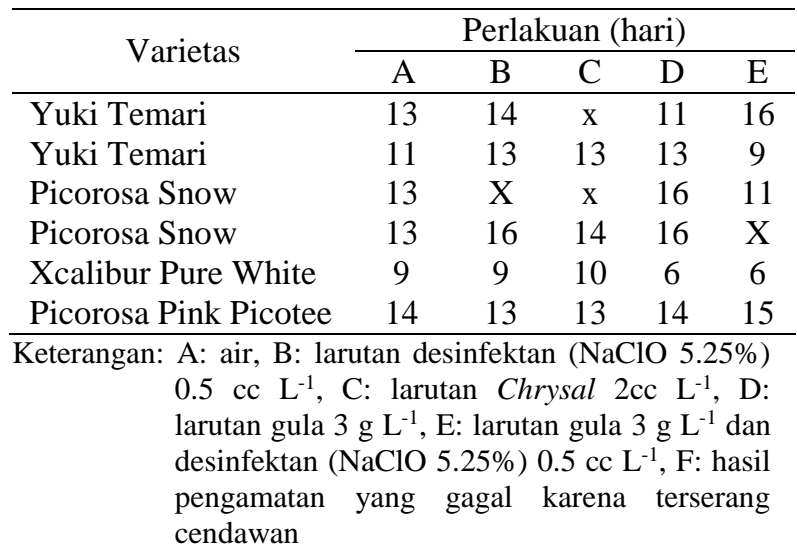

Umur vase life yang diketahui melalui pengamatan ini tidak dapat dijadikan acuan sebagai vase life di tingkat konsumen, disebabkan 
tanaman yang digunakan merupakan tanaman segar yang baru dipanen belum melalui proses pengiriman dan penyimpanan dalam cold storage. Lisianthus disimpan dalam cold storage dengan dipertahankan pada suhu $15{ }^{\circ}$ C. Sakata Seed America (2007) menyatakan bahwa penyimpanan lisianthus dalam ruangan berpendingin harus pada suhu $4^{\circ} \mathrm{C}$. Lisianthus akan lebih baik apabila cold storage dipertahankan pada suhu $4{ }^{\circ} \mathrm{C}$.

\section{KESIMPULAN}

Persentase tanaman produktif masih rendah akibat lisianthus yang roset dan penyakit layu fusarium maka diperlukan pengembangan dari teknik budi daya tersebut. Kegiatan penelitian mampu meningkatkan pengetahuan dan ketrampilan dalam kegiatan budi daya serta manajemen $\mathrm{k}$ ebun yang meliputi perencanaan produksi, pengalokasian tenaga kerja, hingga pengawasan pekerjaan.

\section{DAFTAR PUSTAKA}

American Takii Seed. 2002. Lisianthus - Eustoma grandiflora [Internet]. [diunduh $2009 \mathrm{Jul}$ 2009]. Tersedia pada: http://www.takii.com.

Boodley, J.W. 1998. The Commercial Greenhouse 2nd Edition. New York (US): Delmar Publishers.

Cahyono, F.B. 1999. Chrysanthemum. Dalam: Supari Dh, editor. Seri Praktek Ciputri Hijau Tuntunan Membangun Agribisinis. Jakarta (ID): PT. Media Elex Komputindo.

Harbaugh, B.K. 2007. Lisianthus - Eustoma grandiflorum [Internet]. [diunduh $2009 \mathrm{Jul}$ 17]. Tersedia pada: http://www.books. google.co.id.

Hedy. 2008. Menanam Bunga Lisianthus [Internet]. [diunduh 2008 Jul 20]. Tersedia pada:http://www.hedyagriculturesupportte am.blogspot.com.

Highsun Express. 2008. Lisianthus Cutflowers : Cultural Information [Internet]. [diunduh 2009 Jul 8]. Tersedia pada: http://www.highsun.com.au.
Kantor Klimatologi Kecamatan Pancasari. 2008. Data Cuaca Kantor Klimatologi Kecamatan Pancasari. Tidak dipublikasikan.

Laws, N. 2007. Penilaian Rantai Sektor Florikultur Tropis Indonesia [Internet]. [diunduh 2009 Jul 17]. Tersedia pada:http://www.AMARTAFlorikulturAss essment Jun 07 IN.pdf.

Ledger, S.E., Deroles, S.C., Manson, D.G., Bradley, J.M., Given, N.K. 1997. Transformation of lisianthus (Eustoma grandiflorum). Plant Cell Reports 16:853.

McGovern, R.J., Brent, K.H., Jim, P.P. 1998. Potted Lisianthus : Secrets of Success Disease Control [Internet]. [diunduh 2009 Jul 10]. Tersedia pada: http://www.gcreg. ifas.ufl.edu.

Maryland Cooperative Extension. 2000. Production of Lisianthus as a Cut Flower [Internet]. [diunduh 2008 Des 19]. Tersedia pada: http://www.extension.umd.edu.

Mastalerz, J.W. 1977. The Greenhouse Environment. Canada: John Wiley \& Sons Inc.

Nelson, P.V. 1978. Greenhouse Operation and Management. Reston: Reston Publishing Company Inc.

Sadjad S, Endang, M., Ilyas, S. 1999. Parameter Pengujian Vigor Benih dari Komparatif ke Simulatif. Jakarta (ID): Grasindo.

Sakata Seed America. 2007. Lisianthus - Cut Flower [Internet]. [diunduh $2009 \mathrm{Jul}$ 17]. Tersedia pada: http://www.sakata.com.

Sari IP. 2008. Aplikasi pewarnaan biru pada bunga potong krisan (Dendrathema grandiflora Tzelev.), gerbera (Gerbera jamesonii Bolus), dan mawar (Rosa hybrida L.) [skripsi]. Bogor (ID): Institut Pertanian Bogor. 


\section{LAMPIRAN}

Lampiran 1. Karakteristik berbagai varietas lisianthus

\begin{tabular}{|c|c|c|c|c|c|c|c|c|c|c|c|c|c|}
\hline Parameter & Satuan & Yula Temari & Setti Green & $\begin{array}{c}\text { Paleo } \\
\text { Champagne }\end{array}$ & $\begin{array}{c}\text { Picorosa } \\
\text { Bhue }\end{array}$ & $\begin{array}{c}\text { Rosing } \\
\text { Lavender }\end{array}$ & $\begin{array}{l}\text { Carmen } \\
\text { Violet }\end{array}$ & $\begin{array}{l}\text { Picorosa } \\
\text { Rose Pink }\end{array}$ & Picorosa Snow & Haru Utara & Lination Pink & $\begin{array}{c}\text { Xcalbur Pure } \\
\text { White }\end{array}$ & $\begin{array}{c}\text { Picorosa } \\
\text { Pink Picotee }\end{array}$ \\
\hline Muncul bunga pertama & mst & 7 & 7 & 8 & 6 & 7 & 8 & 8 & 6 & 6 & 6 & 7 & 6 \\
\hline Vuncul bunga kembar & mst & 11 & 13 & 13 & 10 & 10 & 12 & 11 & 10 & 10 & 10 & 11 & 11 \\
\hline 'anen pertama & mst & 13 & 14 & 14 & 11 & 12 & 14 & 12 & 11 & 11 & 11 & 13 & 12 \\
\hline Tingei tanaman & $\mathrm{cm}$ & $93,00 \pm 5,48$ & $77,80=19,25$ & $79,00 \pm 26,08$ & $59,17 \pm 9,41$ & $57,40=8,20$ & $67,75 \pm 9,03$ & $71,90=4,12$ & $58,60=16,94$ & $59,00=10,64$ & $54,6=7,83$ & $91,33 \pm 1$ & $81,75 \pm 4,35$ \\
\hline imlah bunga & kuntum & $9.75 \pm 4,03$ & $6,20=1,64$ & $5,25=0,96$ & $5,50 \pm 1,22$ & $4,60=0,89$ & $7,10=1,20$ & $9,50=1,96$ & $4,60=1,82$ & $50 \pm 5,82$ & $8,20=2,59$ & 3.87 & $=3,30$ \\
\hline Yiameter bunga & $\mathrm{cm}$ & $8,85 \pm 0,58$ & $9,10=0,89$ & $8,90=1,05$ & $6,79 \pm 0,49$ & $6,80 \pm 0,92$ & $7,19=0,84$ & $5,25=0,61$ & $\pm 0,71$ & 0,63 & $=0,57$ & 6,80 & 5,4 \\
\hline anjang tangkai & $\mathrm{cm}$ & $13,88 \pm 2,78$ & $11,70=3,31$ & $13,75 \pm 5,44$ & $15,00 \pm 1,10$ & $13,33 \pm 2,08$ & $13,40=1,84$ & $11,80 \pm 1,23$ & $10,60 \pm 3,65$ & $12,00=1,10$ & $\pm 2,17$ & 15,60 & 14,3 \\
\hline umlah daun mahkota & belai & $20,33 \pm 2,08$ & $22,33=1,15$ & $15,75 \pm 2,06$ & $17,50 \pm 1,73$ & $21,67 \pm 2,52$ & $16,60=1,14$ & $15,88 \pm 2,80$ & $15.67 \pm 2.24$ & $15,70 \pm 3,71$ & $8=4,39$ & 14,60 & $15,00=1,25$ \\
\hline umlah daun & belai & $39,00=11,14$ & $34,00=11,31$ & $36,40 \pm 9,10$ & $23,17 \pm 6,88$ & $30,40 \pm 4,34$ & $36,20 \pm 5,03$ & $38,20=8,77$ & $27,6 \pm 4,56$ & $51,00=22,12$ & $32,80=4,60$ & $52,00 \pm 5,06$ & $44,00=8,79$ \\
\hline lanjang daun & $\mathrm{cm}$ & $9,44 \pm 0,88$ & $7,83=1,75$ & $8,20 \pm 1,64$ & $7,75 \pm 0,99$ & $8,33 \pm 0,58$ & $8,00 \pm 1,22$ & $8,30=0,86$ & $8,20 \pm 1,30$ & $9,17 \pm 1,72$ & $7,20 \pm 1,10$ & $10,45 \pm 0,83$ & $9,67 \pm 0,58$ \\
\hline ebar daun & $\mathrm{cm}$ & $6,33 \pm 1,03$ & $.83=1.44$ & $4,90=0,89$ & $3.92 \pm 0.38$ & $3.67 \pm 0.58$ & $5.10=0.74$ & $5.60=0.74$ & $4,10=0.89$ & $4,50=0.77$ & $3,20=1,10$ & $5,45 \pm 0,44$ & $5.83=0,29$ \\
\hline Yiameter batang & $\operatorname{mm}$ & $7,00+1,00$ & $5,00+0,00$ & $6,00+1,00$ & $4,30=0,82$ & $4,80=0,63$ & $5,40=0,84$ & $5,00 \pm 0,67$ & & & $4,90=0,74$ & $6,90 \pm 0,74$ & $4,90 \pm 0,74$ \\
\hline 'anjang internode & $\mathrm{cm}$ & $11,85 \pm 1,73$ & $11,38=3,78$ & $10,75 \pm 2,87$ & $10,08 \pm 1,43$ & $8,67 \pm 1,53$ & $7,80 \pm 0,75$ & $8,25=1,18$ & $8,20=3,83$ & $9,17 \pm 1,60$ & $7,40=1,52$ & $10,60 \pm 1,35$ & $10,25 \pm 1,71$ \\
\hline 'ercabangan & cabang & $2,30 \pm 0,48$ & $2,90=0,57$ & $2,40 \pm 0,52$ & $2.20 \pm 1,03$ & $2,20 \pm 0,63$ & $2,50=0,85$ & $3,60=0,70$ & $2,20 \pm 0,63$ & $3,50 \pm 0,71$ & $4,10=0,88$ & $4,70 \pm 0,67$ & $3,20=0,63$ \\
\hline
\end{tabular}

